OPEN ACCESS

Edited and reviewed by: Keiji Hirose

Graduate School of Engineering Science, Osaka University, Japan

${ }^{*}$ Correspondence:

Michiya Fujik

fujikim@ms.naist.jp; michiyafujiki@icloud.com Abd Jalil Jalilah

jalilahjalil@unimap.edu.my

TORCID:

Michiya Fujiki orcid.org/0000-0002-3139-9478

Laibing Wang orcid.org/0000-0002-3380-7826 Abd Jalil Jalilah orcid.org/0000-0003-1265-0919

Specialty section:

This article was submitted to Supramolecular Chemistry, a section of the journal Frontiers in Chemistry

Received: 25 August 2020 Accepted: 31 August 2020 Published: 02 October 2020

Citation:

Fujiki M, Wang L, Ogata N, Asanoma F, Okubo A, Okazaki S, Kamite $H$ and Jalilah AJ (2020)

Corrigendum: Chirogenesis and Pfeiffer Effect in Optically Inactive Eull' and $\mathrm{Tb}^{\prime \prime \prime}$ Tris( $\beta$-diketonate) Upon Intermolecular Chirality Transfer From

Poly- and Monosaccharide Alkyl Esters and $\alpha$-Pinene: Emerging Circularly Polarized Luminescence (CPL) and Circular Dichroism (CD).

Front. Chem. 8:598729.

doi: 10.3389/fchem.2020.598729

\section{Corrigendum: Chirogenesis and} Pfeiffer Effect in Optically Inactive $\mathrm{Eu}^{\text {III }}$ and $\mathrm{Tb}^{\text {III }}$ Tris( $\beta$-diketonate) Upon Intermolecular Chirality Transfer From Poly- and Monosaccharide Alkyl Esters and $\alpha$-Pinene: Emerging Circularly Polarized Luminescence (CPL) and Circular Dichroism (CD)

\author{
Michiya Fujiki ${ }^{1 \star \dagger}$, Laibing Wang ${ }^{1 \dagger}$, Nanami Ogata ${ }^{1}$, Fumio Asanoma ${ }^{1}$, Asuka Okubo ${ }^{1}$, \\ Shun Okazaki ${ }^{1}$, Hiroki Kamite ${ }^{1}$ and Abd Jalil Jalilah ${ }^{1,2,3 * t}$ \\ ${ }^{1}$ Division of Materials Science, Graduate School of Science and Technology, Nara Institute of Science and Technology, \\ Ikoma, Japan, ${ }^{2}$ School of Materials Engineering, Universiti Malaysia Perlis, Jejawi, Malaysia, ${ }^{3}$ Centre of Excellence Frontier \\ Materials Research, Universiti Malaysia Perlis, Kangar, Malaysia
}

Keywords: non-covalent interaction, circularly polarized luminescence, circular dichroism, europium, terbium, cellulose, saccharide, terpene

\section{A Corrigendum on}

Chirogenesis and Pfeiffer Effect in Optically Inactive $\mathrm{Eu}^{\mathrm{III}}$ and $\mathrm{Tb}^{\mathrm{III}}$ Tris( $\beta$-diketonate) Upon Intermolecular Chirality Transfer From Poly- and Monosaccharide Alkyl Esters and $\alpha$-Pinene: Emerging Circularly Polarized Luminescence (CPL) and Circular Dichroism (CD) by Fujiki, M., Wang, L., Ogata, N., Asanoma, F., Okubo, A., Okazaki, S., et al. (2020). Front. Chem. 8:685. doi: $10.3389 /$ fchem.2020.00685

In the original article, there were mistakes in Table $\mathbf{1}$ as published. Table $\mathbf{1}$ aimed to compare all $g_{\text {lum }}$ values at specific wavelengths of four $\mathrm{Ln}^{\mathrm{III}}$ tris( $\beta$-diketonates) $\left(\mathrm{Ln}^{\mathrm{III}}: \mathrm{Eu}^{\mathrm{III}}\right.$ and $\left.\mathrm{Tb}^{\mathrm{III}}\right)$ upon intermolecular chirality transfer from CABu, CTA, Glu ( $D$ - and $L-)$, Ara $(D-$ and $L-)$, and $\alpha$ pinene for clarity and readability. However, although the $g_{\text {lum }}$ values described in the main text are correct, most data in the three right-side columns of Table $\mathbf{1}$ are incorrectly displayed. Also, in Table 1 caption, $D$-/L-glucose pentameyhyl esters should be $D$-/L-glucose pentamethyl esters. The corrected Table 1 with corrected numerical values in the three right-side columns and corrected caption appears below.

Also, there was an error in Introduction. The sentence starting with "Particularly, chirogenesis in metal coordination chemistry by the chirality transfer has long been one of the central subjects in inorganic chemistry 1 (Mason and Norman, 1965...)" should read as follows: "Particularly, chirogenesis in metal coordination chemistry by the chirality transfer has long been one of the central subjects in inorganic chemistry (Mason and Norman, 1965...)".

The authors apologize for these errors and state that this does not change the scientific conclusions of the article in any way. The original article has been updated. 
TABLE 1 | CPL characteristics (dissymmetry ratio, glum in $10^{-2}$ at specific wavelength) of Eu $\mathrm{u}^{\text {III }}$ and Tbll' coordinated with three $\beta$-diketonates as achiral ligands embedded in two polysaccharide alkyl esters (CABu and CTA), $D$-/L-glucose pentamethyl esters ( $\boldsymbol{D}$-/L-Glu), and $D$-/L-Arabinose tetramethyl esters (D-/L-Ara).

\begin{tabular}{|c|c|c|c|c|c|c|c|c|}
\hline \multirow[t]{2}{*}{$\begin{array}{l}\text { Ln"I' tris( } \beta \text { - } \\
\text { diketonates) }\end{array}$} & \multirow[t]{2}{*}{$\begin{array}{c}\text { CABu } \\
g_{\text {lum }} / 10^{-2}(\mathrm{~nm})\end{array}$} & \multirow[t]{2}{*}{$\begin{array}{c}\text { CTA } \\
g_{\text {lum }} / 10^{-2}(\mathrm{~nm})\end{array}$} & \multicolumn{2}{|c|}{$\begin{array}{c}\text { Glu } \\
g_{\text {lum }} / 10^{-2}(\mathrm{~nm})\end{array}$} & \multicolumn{2}{|c|}{$\begin{array}{c}\text { Ara } \\
g_{\text {lum }} / 10^{-2}(\mathrm{~nm})\end{array}$} & \multicolumn{2}{|c|}{$\begin{array}{c}\alpha-\text {-pinene } \\
g_{\text {lum }} / 10^{-2}(\mathrm{~nm})\end{array}$} \\
\hline & & & $D-$ & $L-$ & $D-$ & $L-$ & $(1 R)$ & (1S) \\
\hline $\mathrm{Eu}(\mathrm{fod})_{3}$ & $\begin{array}{l}+6.71(593)^{\mathrm{a}} \\
-0.59(613)^{\mathrm{b}}\end{array}$ & $\begin{array}{l}+4.63(593)^{\mathrm{a}} \\
-0.40(613)^{\mathrm{b}}\end{array}$ & $\begin{array}{l}+1.05(594)^{\mathrm{a}} \\
-0.19(612)^{\mathrm{b}}\end{array}$ & $\begin{array}{l}-0.81(596)^{\mathrm{a}} \\
+0.08(613)^{\mathrm{b}}\end{array}$ & $\begin{array}{l}+0.19(593)^{\mathrm{a}} \\
-0.02(607)^{\mathrm{b}}\end{array}$ & $\begin{array}{l}-0.30(591)^{\mathrm{a}} \\
+0.06(611)^{\mathrm{b}}\end{array}$ & $\begin{array}{l}-0.49(593)^{\dagger} \\
+0.05(613)^{f}\end{array}$ & $\begin{array}{l}+0.41(593)^{f} \\
-0.04(613)^{f}\end{array}$ \\
\hline $\mathrm{Eu}(\mathrm{dpm})_{3}$ & n.d. ${ }^{9}$ & n.d. ${ }^{9}$ & n.d. ${ }^{9}$ & n.d. ${ }^{9}$ & n.d. ${ }^{9}$ & n.d. ${ }^{9}$ & n.d. ${ }^{9}$ & n.d. ${ }^{g}$ \\
\hline $\mathrm{Tb}(\mathrm{dpm})_{3}$ & $\begin{array}{l}-0.53(491)^{\mathrm{c}} \\
+0.37(537)^{\mathrm{d}} \\
-0.59(547)^{\mathrm{e}}\end{array}$ & $\begin{array}{c}-0.44(489)^{\mathrm{C}} \\
- \\
+0.80(547)^{\mathrm{e}}\end{array}$ & n.d. ${ }^{9}$ & n.d. ${ }^{9}$ & n.d. ${ }^{9}$ & n.d.g & $\begin{array}{l}\text { n. } d^{g}(\sim 490) \\
+0.44^{d}(537) \\
-0.13^{e}(547)\end{array}$ & $\begin{array}{l}\text { n. } d^{g}(\sim 490) \\
-0.49^{d}(537) \\
+0.34^{\mathrm{e}}(548)\end{array}$ \\
\hline
\end{tabular}

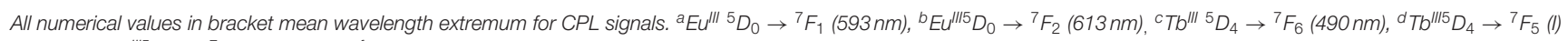
$(540 \mathrm{~nm}),{ }^{e} T \mathrm{~Tb}^{\mathrm{Ill}} \mathrm{D}_{4} \rightarrow{ }^{7} F_{5}$ (II) $(552 \mathrm{~nm}),{ }^{f}$ Data were taken from literature (Jalilah et al., 2018). ${ }^{9}$ Not characterized or no data.

\section{REFERENCES}

Jalilah, A. J., Asanoma, F., and Fujiki, M. (2018). Unveiling controlled breaking of the mirror symmetry of $\mathrm{Eu}(\mathrm{Fod})_{3}$ with $\alpha$-/ $\beta$-pinene and BINAP by circularly polarised luminescence (CPL), CPL excitation, and ${ }^{19} \mathrm{~F}-\rho^{31} \mathrm{P}\left\{{ }^{1} \mathrm{H}\right\}$ NMR spectra and mulliken charges. Inorg. Chem. Front. 5, 2718-2733. doi: 10.1039/C8QI00509E

Mason, S. F., and Norman, B. J. (1965). Outer-sphere co-ordination and optical activity in transition-metal complexes. Chem. Commun. 335-336. doi: $10.1039 / \mathrm{c} 19650000335$
Copyright (c) 2020 Fujiki, Wang, Ogata, Asanoma, Okubo, Okazaki, Kamite and Jalilah. This is an open-access article distributed under the terms of the Creative Commons Attribution License (CC BY). The use, distribution or reproduction in other forums is permitted, provided the original author(s) and the copyright owner(s) are credited and that the original publication in this journal is cited, in accordance with accepted academic practice. No use, distribution or reproduction is permitted which does not comply with these terms. 